\title{
RADIOLOGICAL FINDINGS IN EARLY VESICO-URETERAL REFLUX AMONG SPINAL CORD INJURY PATIENTS
}

\author{
By Oliver E. Cobb, M.D., and Herbert, S. Talbot, M.D. \\ Spinal Cord Injury and Urology Service, \\ Veterans Administration Hospital, West Roxbury, Massachusetts, U.S.A.
}

CURRENT interest in vesico-ureteral reflux has been, in considerable degree, stimulated and sustained by the frequency with which it occurs as a complication of neurogenic vesical dysfunction in spinal cord injury patients. Whatever may be its cause in others, there is good evidence that among these patients it results from infection in the ureteral wall. As this advances, other ureteral dysfunctions may develop, leading to poor drainage of the upper urinary tract and enhanced vulnerability of the kidney to infection. It seems important, therefore, to try to relate the demonstration of reflux to abnormalities observed on intravenous pyelography, first, because this will focus attention upon those patients among whom reflux will be a likely finding, and second, because these observations may increase our understanding of its development and significance. Marshall has reported on such findings in children, among whom reflux has been widely studied (McGovern, et al. I960; Marshall, I962).

The standard method of demonstrating reflux is by the cystogram. Its appearance, however, is notably capricious, even when it is known to have been present before and especially when it is not of long standing. The term 'early reflux', in the present context, refers merely to the fact that this was its first appearance. A number of more elaborate methods for its demonstration have been developed, including delayed cystograms, cinéfluoroscopy and radioisotope studies. All are useful but in clinical applications may well be reserved for those instances in which reflux is suspected but not demonstrable at the first try, or for more refined investigation of its dynamics. Hence the importance of being able to recognise, in such a universal screening procedure as the intravenous pyelogram, signs which raise a strong suspicion that reflux may exist. The present study was undertaken with a view to estimating how well such signs correlate with the findings on the cystogram.

Method. The study covered 40 spinal cord injury patients in whom vesico-ureteral reflux was first demonstrated during the period 1955-1963. Only those were included who had had both intravenous pyelograms and cystograms within a suitably short period of time. In 36 of the 40, the interval was a month or less; in four it was three months. (Ideally, this interval should be no longer than the time it takes for the urinary tract to be cleared of all the contrast medium excreted during the intravenous pyelogram, but in a retrospective study a wide latitude had to be allowed.) All the patients were males who had been generally healthy prior to the spinal cord injury and had no histories of prior urinary tract disease. One was found to have congenital absence of the left kidney; no other anomalies were noted. All had chronic bacteriuria.

Routine intravenous pyelography included films made prior to and 5, IO, and I5 minutes after injection of the contrast medium, with an additional post-voiding film when possible. For the cystograms, the medium was introduced by gravity, from a height of $20 \mathrm{~cm}$., until the fluid stopped running into the bladder or the patient experienced discomfort or perspired. The catheter was then clamped, a film exposed immediately, and another I5 minutes later. Earlier experience has shown that, in this type of patient, the yield in demonstration of reflux is but slightly increased by taking additional films at intervals during the next two hours. Deliberate over-distention of the bladder, as prac- 
tised by some investigators, may not only be prejudicial to the patient (in those with high spinal cord lesions it may produce dangerous reflex phenomena) but distorts any attempt at a dynamic interpretation.

Since one of the patients had only one kidney, 79 sides were considered. Reflux was designated as partial when the column of regurgitant fluid extended only part way up the ureter, total when it filled the renal pelvis and calyces.

\section{FINDINGS AND DISCUSSION}

Among the 40 patients, 57 of the 79 sides showed reflux. A suggestion of its transitory character is seen in the fact that on eight sides it appeared at once but was gone I 5 minutes later when the second film was exposed. As might be expected in seven of the eight, this was partial reflux. By the time it involves the entire upper tract, it is more likely to be consistent, suggesting a more severe and less probably reversible dysfunction. Table I shows the appearance of reflux on the first and second films according to its extent.

\section{TABLE I}

Appearance of Reflux on Immediate and I5-Minute Films, according to its Extent

\begin{tabular}{|c|cc|c|}
\hline Type of reflux & \multicolumn{3}{|c|}{ Number of sides involved } \\
& $\begin{array}{c}\text { Immediate } \\
\text { film only }\end{array}$ & $\begin{array}{c}\text { I 5-minute } \\
\text { film only }\end{array}$ & Both films \\
\hline Partial & 7 & 7 & 4 \\
Total & I & 29 & 9
\end{tabular}

In 17 patients the finding was bilateral, in 23 unilateral. The extent of the reflux in these is shown in Table II. In the bilateral cases 73 per cent. of the sides involved showed total reflux; in the unilateral 6I per cent. This suggests, that the longer time required for reflux to become total enhances the likelihood of bilateral involvement, but the series is too small for statistical evaluation. A few patients with total unilateral reflux have been followed for years with no evidence of involvement of the other side, but this is rare.

\section{TABLE II}

Extent of Reflux, by Number of Sides involved, in Bilateral and Unilateral Lases

\begin{tabular}{|c|c|c|c|c|} 
Patients with & \multicolumn{1}{|c|}{ Total } & P. tial & $\begin{array}{c}\text { One side total } \\
\text { One side partial }\end{array}$ & $\begin{array}{c}\text { Total } \\
\text { patients }\end{array}$ \\
\hline Bilateral Reflux & I I (both sides) & 3 (both sides) & 3 & I7 \\
\hline Unilateral Reflux & I 4 & 9 & & 23 \\
\hline
\end{tabular}

The intravenous pyelograms were interpreted as normal in 10 of the 40 patients. Each of the remaining 30 showed one or more of Io recognisable abnormalities, varying in frequency and significance; five involved the kidney and 
five the ureter. Table III indicates the association of these findings with the demonstration of reflux by cystogram.

As might have been expected, impaired renal function was not often encountered in this series of relatively early cases. Determined on the basis of little or no contrast medium appearing on the five-minute film, it was seen only six times; in every instance reflux was present on that side.

\section{TABLE III}

Frequency of Abnormalities on Intravenous Pyelograms suggesting Reflux

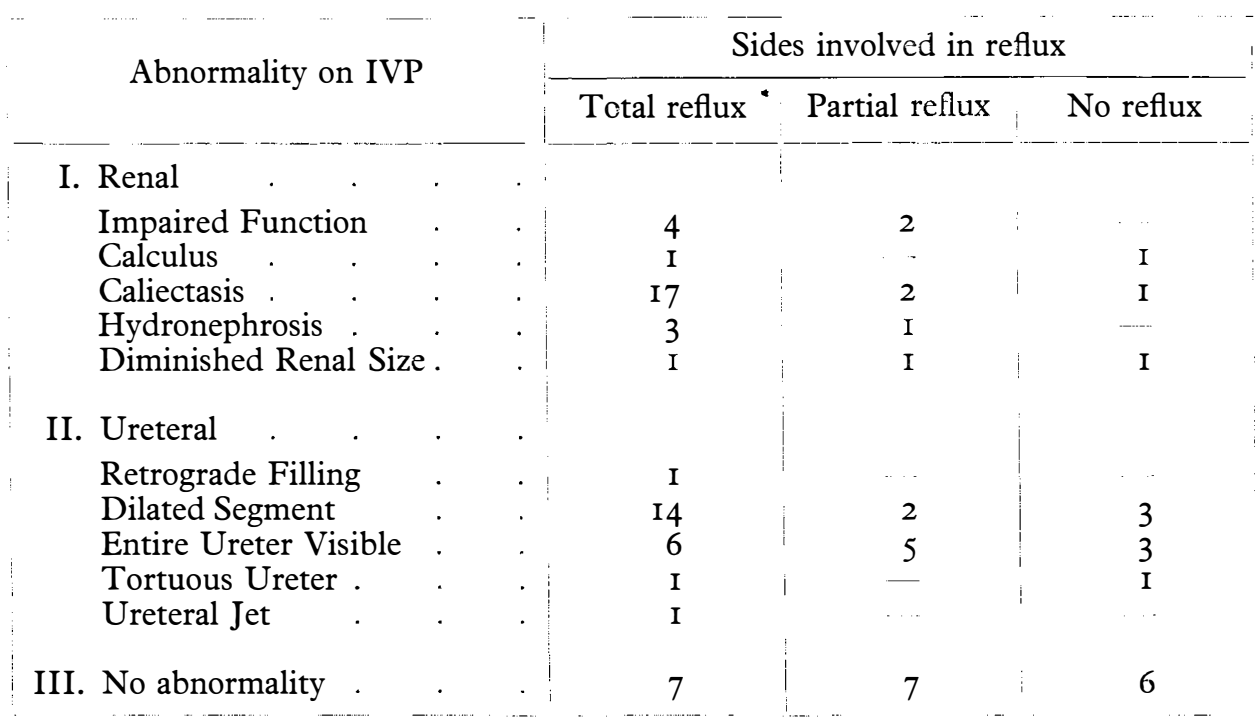

Calculus was found only twice, once in association with reflux on that side, once in a patient who had no reflux at the time but who had since developed it on the other side. In another series of 60 patients with reflux followed for a considerable period, the incidence of calculus was higher (Talbot $e t$ al., in preparation). Among these, only two of 28 patients under observation for less than five years had calculi, but of 32 followed for longer, stones were found in I7. It would appear, therefore, that reflux or its associated changes or both, if sufficiently prolonged, may favour calculus formation.

Caliectasis, usually wi slunting and distortion, was the commonest of the renal abnormalities, appear .1 g in $\mathrm{I} 7$ of th. 39 sides with total reflux, but only twice among I8 with partial reflux. Even in c servations limited to I 5 minutes, failure of the regurgitant fluid to go all the way to the kidney does, in fact, represent a lesser degree of dysfunction as expressed by this important change. It is of some interest that caliectasis was seen only once among 22 sides without reflux, a lower incidence than might have been expected among patients with a predilection for chronic pyelonephritis unless its intimate relationship with reflux is accepted. In general, the kidney seen after prolonged reflux is indistinguishable, radiologically and histologically, from any other kidney with pyelonephritis, and all the calyces are involved (Hodson \& Edwards, I960; Smith, I962). In an occasional early case, 


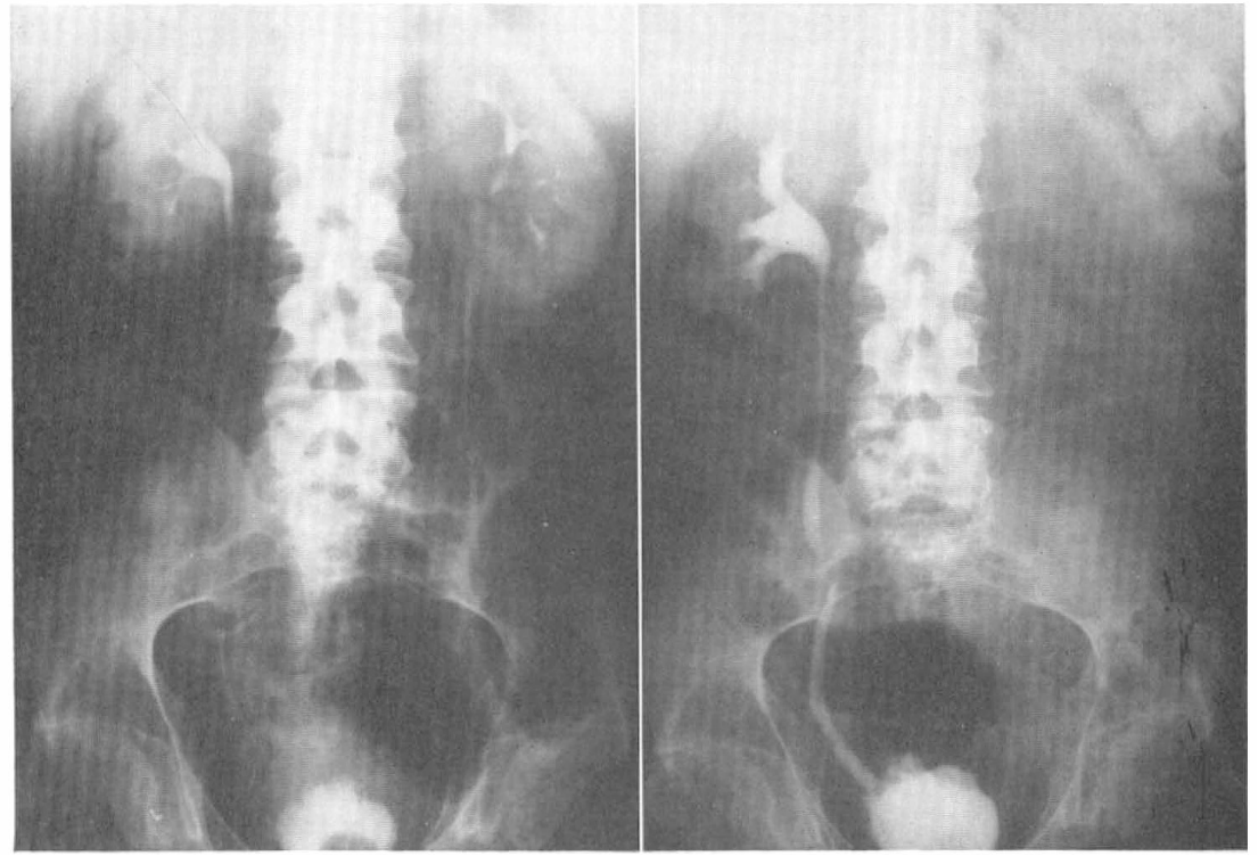

(A)

(B)

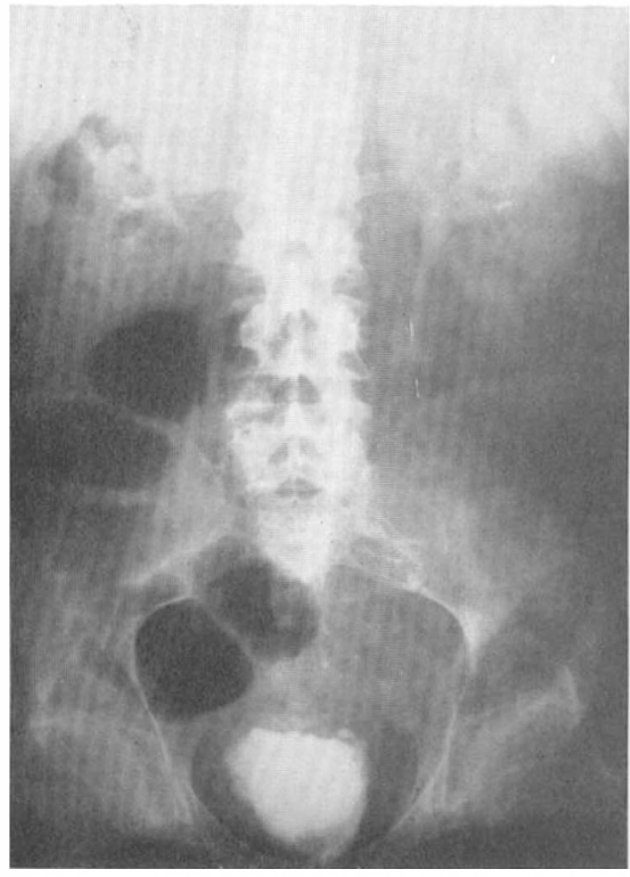

FIG. I

A. Intravenous pyelogram: prominent upper calyx, right.

B. Cystogram (first film): reflux, right.

C. Cystogram (second film): reflux, bilateral.

(C) 
however, a single upper calyx may alone be involved; this has also been noted in children (Berg, personal communication). Its significance in relation to upper urinary tract dynamics is not yet clear (figs. I and 2).

Marshall (I962) found a 50 per cent. incidence of hydronephrosis in children with reflux, but in the present study this was an uncommon finding, probably because the reflux was generally of short duration. When it did appear, the hydronephrosis was not associated with an increase in the size of the kidney, in contrast to

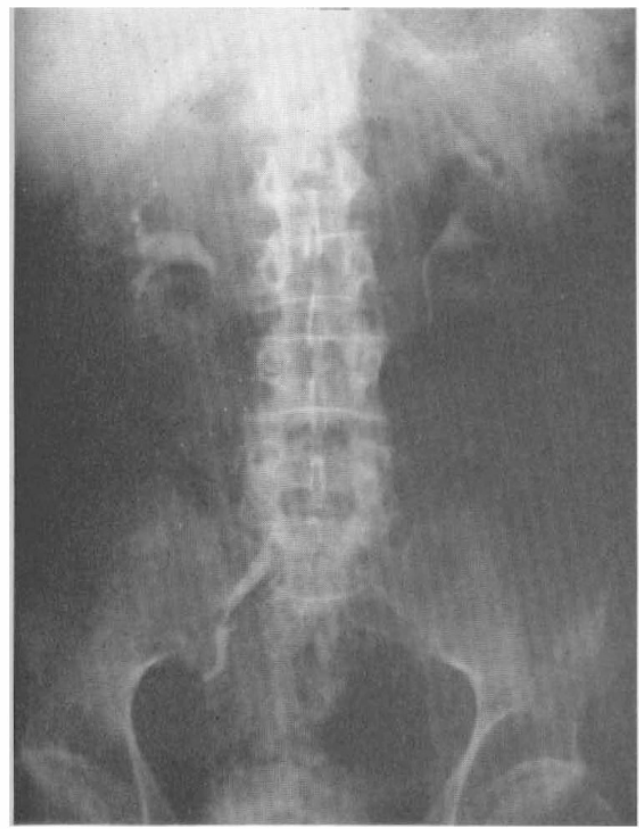

(A)

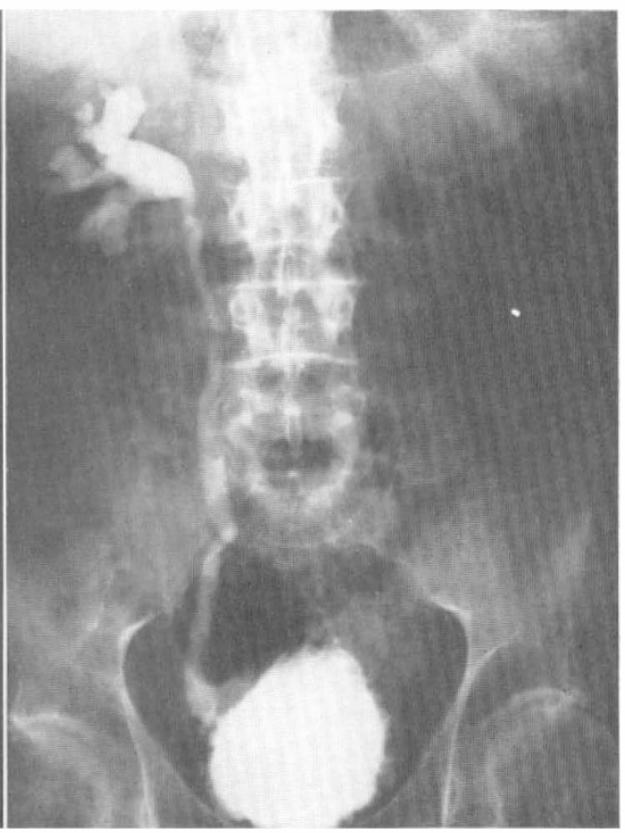

(B)

FIG. 2

A. Intravenous pyelogram: dilatation of lower ureter, right.

B. Cystogram: reflux, right.

what is usually seen when the cause is high ureteral or uretero-pelvic obstruction. It may be that its occurrence in this series was so late a phenomenon that it was accompanied by parenchymal atrophy.

On the other hand, diminution in the size of the kidney was even less frequent. A disparity was considered significant if there was a difference in size of $\mathrm{I} \mathrm{cm}$. or more between the two kidneys, or if either measured less than II $\mathrm{cm}$. in its long axis. Only three of the 79 kidneys met either criterion, two with reflux and one without. Again it may be inferred that the train of events had not yet reached the stage of atrophy.

Among ureteral changes on the intravenous pyelogram, the most conclusive is actual retrograde filling of one ureter with material which has reached the bladder from the other. This can be demonstrated only when there is absent or delayed excretion on the involved side. In the present study it was observed only once and confirmed by the appearance of total reflux on the cystogram. 
Dilatation of the ureter is the most common of the ureteral findings on the intravenous pyelogram which suggest the existence of reflux. It is frequently segmental in distribution and most often involves the lower segment first. Occurring without mechanical obstruction, it is due to local inflammatory changes in the wall of the ureter which impair its contractility. This, in turn, disrupts the mechanism whereby contraction of the lower ureter provides a dynamic valve effect. Dilatation was seen in I6 of 57 sides with reflux, in three of 22 without it (figs. 2 and 3).

Visualisation of the full length of the ureter occurred I I times when reflux was present, three times in its absence. It is another evidence of ureteral dysfunction, and patients who show this sign, together with those whose ureters are dilated, are entitled to further investigation if reflux is not demonstrated on the cystogram. Filling of the entire ureter cannot be explained-in adults at least-as due simply to overflow from a full bladder. It represents partial breakdown of the propulsive mechanism, of which reflux is another evidence (fig. 3).

A tortuous ureter by itself was found once with reflux and once without. It is evidence of long-standing obstruction, whether functional or mechanical and, therefore, of no great value as a clue in early cases.

Ureteral jet was observed only once, in a patient with bilateral total reflux. It has been reported as a common finding among children with infection and reflux, again emphasising this association, and has also been seen in adult females with a history of infection (Nik-Nevin et al., I962) (fig. 4).

None of these signs, renal or ureteral, is pathognomonic of reflux. Some are probably of no great importance. Caliectasis or ureteral dilatation, however, or any other evidence of the failure of ureteral propulsion in the absence of mechanical obstruction should raise a strong suspicion that reflux may be present. Such changes are not, in a strict sense, either causes or effects of reflux but, rather, related dysfunctions arising from a common cause. Infection is the thread that unites them. Hanley (I962) found that reflux could occur in 'anatomically normal' urinary tracts in certain inflammatory conditions; he describes lower ureteral stasis and reflux with tuberculosis of the bladder, and transitory reflux in Io of 50 patients with acute or sub-acute cystourethritis. Studies on patients with neurogenic vesical dysfunction have shown that infection may advance from the bladder to the kidney through the ureteral wall, and that in doing so, it first causes lower segment dilatation and reflux (Talbot, I958).

The concept that reflux may result from infection of the ureteral wall helps to explain its inconstant character. Inflammation may wax and wane and relatively slight changes may set off or alleviate the malfunction. As the pathological process becomes more extensive and less liable to reversal, so will be the physiological alterations to which a whole spectrum of radiologic signs may then be logically related. Reflux occurs early in the sequence of dysfunctions because the lower portion of the ureter is, by propinquity, most vulnerable to bacterial invasion from the bladder. If the process continues, the malfunction will spread to the upper ureter, pelvis and calyces, by which time pyelonephritis will have developed. Reflux is thus, on the one hand, a result of infection; on the other, a dysfunction that favours the further advance of infection toward the kidney.

The distinction between total and partial reflux as evidence of severity is not entirely valid when based on a single examination. Repeated studies are necessary in order to establish the constancy of the findings. Even more important is the 


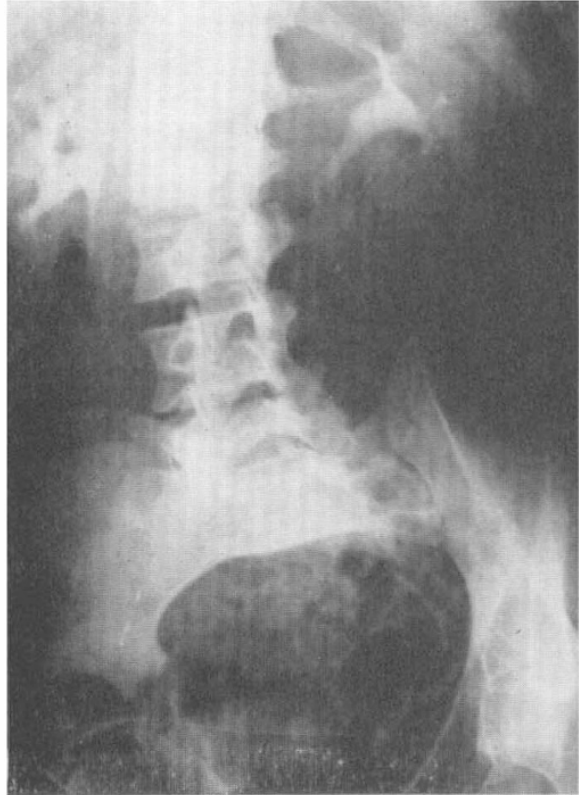

(A)

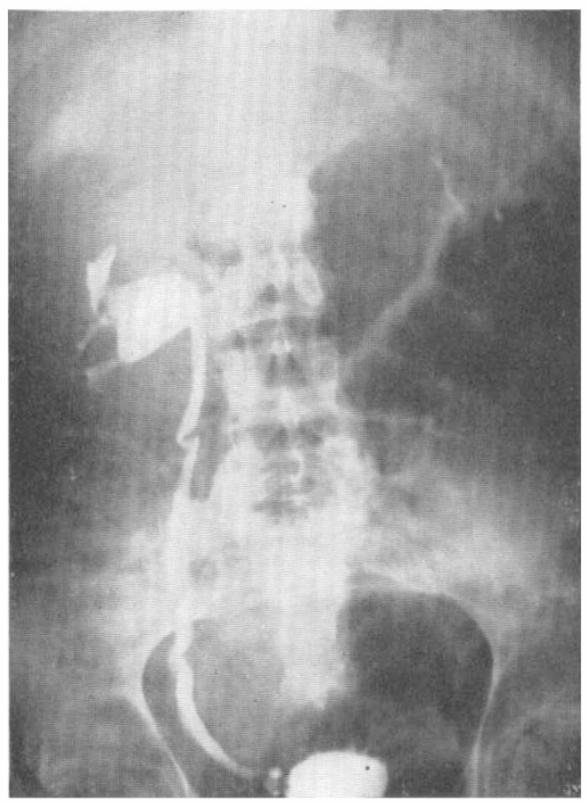

(C)

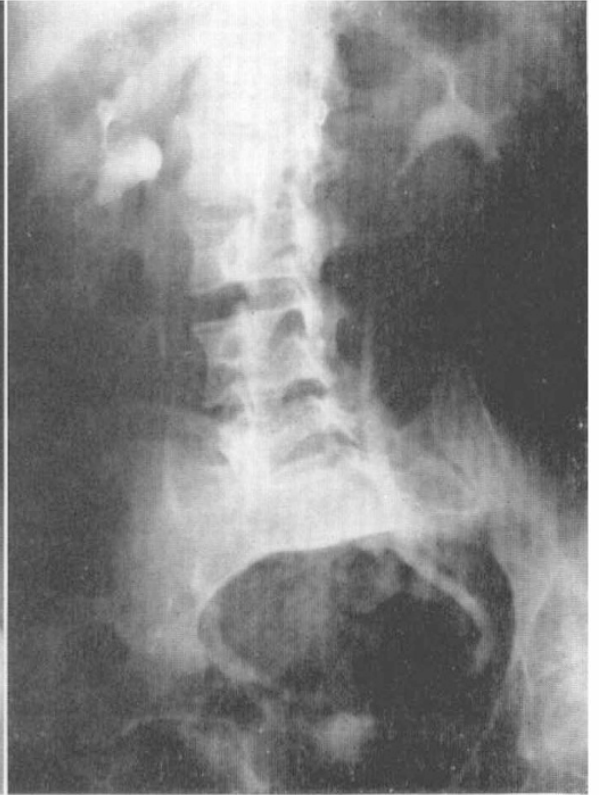

(B)
FIG. 3

A. Intravenous pyelogram (5-minute film): calyceal dilatation, right.

B. Intravenous pyelogram (IO-minute film): dilatation of lower ureter, right; visualisation of full length of ureter, left, with dilatation of lower half.

C. Cystogram: reflux, bilateral. 
determination of whether or not the ureter can compensate for reflux; that is, can it empty itself during or at the end of voiding, or is the column of fluid pushed higher. Fluoroscopic studies, with ciné or spot films, have shown such compensation to be very rare with total reflux. With partial reflux it may or may not be seen-a point of considerable prognostic value (Talbot and Perlmutter, 1964). But the findings on a single cystogram, although not conclusive, may still be significant in the study of a homogeneous group. The purpose of the present report is to

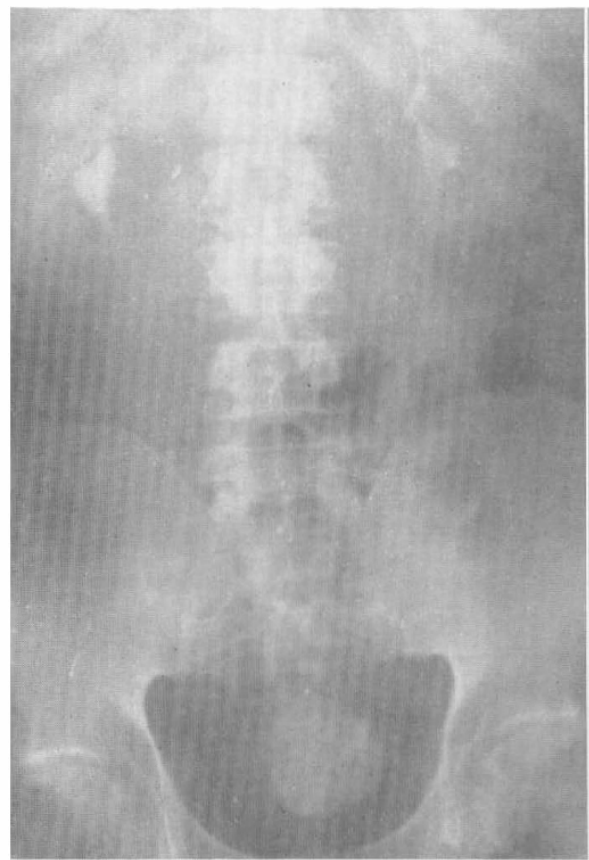

(A)

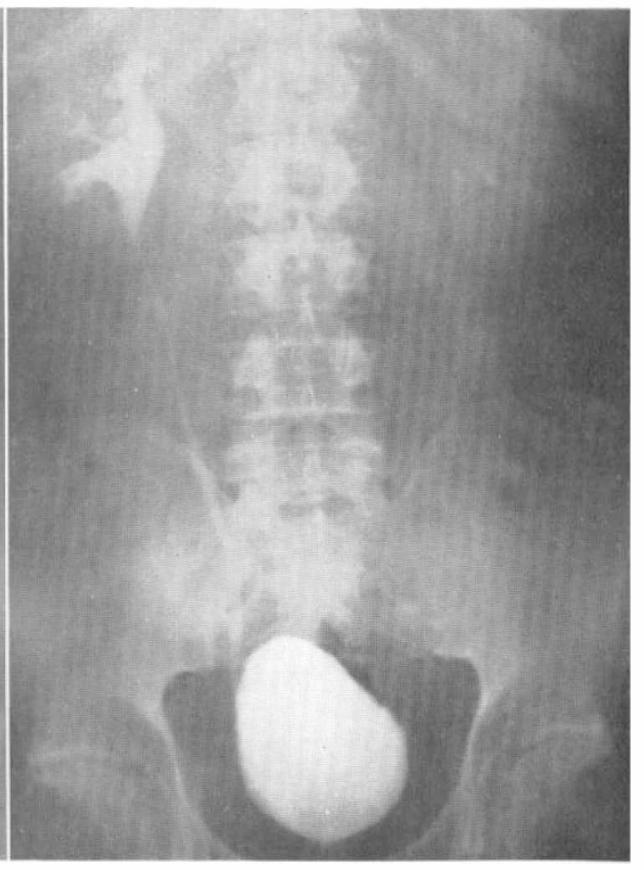

(B)

FIG. 4

A. Intravenous pyelogram: jet, left.

B. Cystogram: reflux, bilateral.

emphasise the functional rather than the anatomical consideration of reflux. This leads to useful inferences in relating it to abnormalities on the intravenous pyelogram.

\section{SUMMARY}

I. A normal intravenous pyelogram does not exclude the possibility of vesicoureteral reflux. Of 40 patients who showed reflux on cystograms, Io had intravenous pyelograms which showed no abnormality.

2. On the other hand, 30 of these patients ( 75 per cent.) had intravenous pyelograms which were abnormal. Some of the changes, although slight, were clearly significant. Others might have been coincidental.

3. Although not pathognomonic, the most important changes are caliectasis and ureteral dilatation without mechanical obstruction. 
4. The significance of reflux may be gauged by its extent, its duration, its constancy, and the capacity of the ureter to compensate. A single cystogram is not sufficient for evaluation of these factors, but the extent of the reflux, as revealed in this study, correlates well with observed abnormalities in the intravenous pyelogram.

5. The radiological observations support the view that, in this group of patients, reflux results from inflammatory changes in the lower ureteral segment.

\section{RÉSUMÉ}

I. Une pyélographie intraveineuse n'exclut pas la présence du reflux vésico-uréteral. Sur 40 malades étudiés, présentant un reflux aux cystogrammes, Io ont montréune urographie normale.

2. d'un autre côté, 30 de ces malades $(75 \%)$ montrèrent des urogrammes anormaux. Quelques perturbations, quoique légères, étaient significatives et il est possible que d'autres aient été des coincidences.

3. Quoique non pathognomoniques, les perturbations les plus importantes sont les signes de rétentions calicielles et les dilatations urétérales sans obstruction mécanique.

4. La signification du reflux peut être estimée par son degré, sa durée, sa constance et la capacité de compensation de l'uretère. Un seul cystogramme n'est pas suffisant pour l'évaluation de ces facteurs, mais l'extension du reflux tel qu'il est révélé dans cette étude est en corrélation avec les anomalies observées dans l'urographie intra-veineuse.

5. Les observations radiologiques supportent la thèse, que dans ce groupe de malade, le reflux serait le résultat d'atteintes inflammatoires du segment inférieur de l'urétère.

\section{ZUSAMMENFASSUNG}

I. Ein normales intravenöses Pyelogram schliesst nicht die Möglichkeit eines vesicoureteralen Reflux aus. Von 40 Patienten mit Reflux hatten io ein normales intravenöses Pyelogramm.

2. Andrerseits hatten 30 dieser Patienten (75\%) ein pathologisches I.V.P. Einige dieser Veränderungen, obwohl leichten Grades, waren einwandfrei.

3. Obgleich nicht pathognomonisch, die wichtigsten Veränderungen sind Kaliektasis und ureterale Dilatation ohne mechanische Obstruktion.

4. Die Bedeutung des Reflux kann gemessen werden bei Ausdehnung, Dauer, Permanenz und Adaptationsfähigkeit des Ureter. Ein Cystogramm genügt nicht für die Analyse dieser Faktoren, aber die Ausdehnung des Reflux, wie hier beschrieben, ist in guter Korrelation mit den beobachteten Veränderungen im I.V.P.

5. Die radiologischen Befunde unterstützen die Ansicht, dass bei diesen Patienten entzündliche Veränderungen des unteren ureteralen Abschnitts die Ursache des Reflux sind.

\section{REFERENCES}

Berg, S. Personal communication.

Gross, K. E. \& SANDERSon, S. S. (196I). Radiology, 77, 573.

HANLEY. H. G. (1962). Brit. F. Urol. 34, 283.

Hodson. C J. \& EDwards, D. (1960). Clin. Radiol. I1, 219.

McGovern, J. H., Marshall, V. F. \& Paquin, A. J., Jr. (I960). F. Urol. 83, I22.

MARShall, F. C. (1962). F. Urol. 87, 68I.

Nik-Nevin, I., Cline, F. A. \& HaUG, T. M. (I962). Radiology, 79, 933.

Rooney, D. R. (1961). Vesico-ureteral reflex in children. Amer. F. Roentgenol. 86, 545.

SMith, J. F. (1962). F. Clin. Path. I5, 522.

Talbot, H. S. (1958). F. Amer. med. Ass. 168, 1595.

Talbot, H. S., Mahoney, E. M., Jarrett, J. E. \& Cobb, O. E. Uretero-vesical dynamics in relation to reflux. In preparation.

TAlbot, H. S. \& PeRlmutTer, A. D. The role of inflammatory changes in disturbed ureterodynamics. Transactions of the 2nd International Symposium on Pyelonephritis, Boston I964. To be published.

R 